\title{
Relationship between urinary and blood glucose in diabetic children
}

\author{
N. K. GRIFFIN, M. A. SMITH, P. A. JENKINS, G. WERTHER, AND J. D. BAUM \\ Department of Paediatrics, John Radcliffe Hospital, Headington, Oxford
}

SUMMARY The relationship of urine glucose concentration with 'average' blood glucose concentration for the corresponding period was investigated in 10 juvenile diabetics during the performance of 15 inpatient metabolic profiles. $0 \%$ glycosuria was associated with 'average' blood glucose concentrations $<6.4 \mathrm{mmol} / 1(<115 \mathrm{mg} / 100 \mathrm{ml}), 2 \%$ glycosuria with concentrations $>8.6 \mathrm{mmol} / \mathrm{l}$ $(>154 \mathrm{mg} / 100 \mathrm{ml})$, and over $5 \%$ glycosuria with concentrations $>11 \cdot 3 \mathrm{mmol} / 1(>204 \mathrm{mg} / 100 \mathrm{ml})$. Urinary glucose loss was large $(>278 \mathrm{mmol}$; $>5 \mathrm{~g})$ when the 'average' blood glucose was $>11 \cdot 1$ $\mathrm{mmol} / \mathrm{l}(>200 \mathrm{mg} / 100 \mathrm{ml})$. Because many diabetics have blood glucose concentrations up to $11 \cdot 1 \mathrm{mmol} / \mathrm{l}$, it is advantageous if glycosuria up to $5 \%$ is detectable by routine home urine tests. The 2-drop Clinitest method detects glycosuria up to $5 \%$ without significant loss of accuracy and is recommended in preference to the 5-drop method.

Diabetic control in children with diabetes is usually assessed by frequent measurements of urine glucose concentration. This test is performed by the child or his parents using a simple proprietary system. Clinitest tablets (Ames Company, Slough) are widely used and, in conventional use, 5 drops of urine plus 10 drops of water generate a colour indicating a reducing sugar concentration in the range from 0 to $2 \mathrm{~g} / 100 \mathrm{ml}(0$ to $111 \mathrm{mmol} / \mathrm{l})$. Alternatively, the 2-drop Clinitest method (Belmonte et al., 1967) may be used; this uses 2 drops of urine plus 10 drops of water generating a colour range corresponding to a urinary-reducing sugar concentration from 0 to $5 \mathrm{~g} / 100 \mathrm{ml}(0$ to $278 \mathrm{mmol} / \mathrm{l})$.* Whichever system of urine testing is used, the urine glucose concentration is a retrospective and indirect measurement of the blood glucose concentration from the time that the bladder was last emptied. We studied the relationship between urinary and blood glucose concentrations measured over a 24-hour period in hospital in a group of diabetic children.

* Special colour charts for this colour range are available from Ames Company.

The Hospital for Sick Children, London

N. K. GRIFFIN, senior registrar

Department of Paediatrics, John Radcliffe Hospital, Heading-

ton, Oxford

M. A. SMITH, medical laboratory scientific officer

P. A. JENKINS, senior medical laboratory scientific officer

G. WERTHER, research fellow

J. D. BAUM, clinical reader in paediatrics

\section{Methods}

The study formed part of a larger investigation of metabolic profiles (N. K. Griffin et al. in preparation) performed on diabetic children to assess their total control. At the time of the study all the children were reasonably well controlled according to usual criteria. Informed consent was obtained from the children and their parents before admission to hospital, and throughout the study the children were on their normal diets and their physical activities were not restricted.

Fifteen 24-hour studies were performed on 10 children ( 3 girls and 7 boys). The ages of the children at the time of the study ranged from 10 to 16 years (mean 13.5) and they had been diabetic for 0.1-8 years (mean 4.2). All the studies were performed with the children on once-daily injections of insulin: 4 on Lente (unspecified manufacturer), 4 on Rapitard (Novo*), and 7 on Monotard (Novo*), with the daily dose ranging from 22 to 88 units (mean 47).

The patients were admitted to hospital in the evening and the study began the next morning. A plastic cannula was inserted into a peripheral vein and kept patent with heparinised saline between samplings. Blood samples were withdrawn for blood glucose measurements during the day before each main meal $(7.30,12.00$, and 18.00 hours) and 15 , 30 , and 60 minutes after each meal. Samples were *Novo Insulins, Copenhagen, Denmark. 
also drawn before snacks $(10.30,15.00$, and 20.30 hours) and during the night $(23.00,02.00,05.00$, and 07.00 hours). Samples for blood glucose were placed in $5 \%$ perchloric acid and the glucose subsequently measured using the hexokinase method (Bergmeyer, 1974).

Blood glucose measurements for each child were plotted against time and individual points were joined. From this line the blood glucose concentration was read at 30-min intervals throughout the 24 hours and the 'average' blood glucose concentration was calculated for each period between urine voidings.

Each urine sample voided was collected separately in plastic containers and the volume measured. An aliquot was placed in a separate fluoride tube, and the urine glucose concentration estimated using a glucose analyser with glucose oxidase (Analox Instrum(nts).

The mean interval between voidings during the day was 2.7 hours (range $0.75-5$ ). The overnight urine was passed as a single voiding in the morning: the mean time since the previous voiding for this specimen was 10 hours (range $8 \cdot 5-11$ ). The results of the overnight samples were analysed separately from the urine voidings and blood glucose measurements made during the day.

\section{Results}

Validation of the 2-drop urine test. 26 urine samples were tested for reducing sugar concentration using the 2-drop urine test and the corresponding glucose concentration was measured using the glucose analyser. The correlation is shown in Fig. 1. All but two Clinitest readings were accurate to within

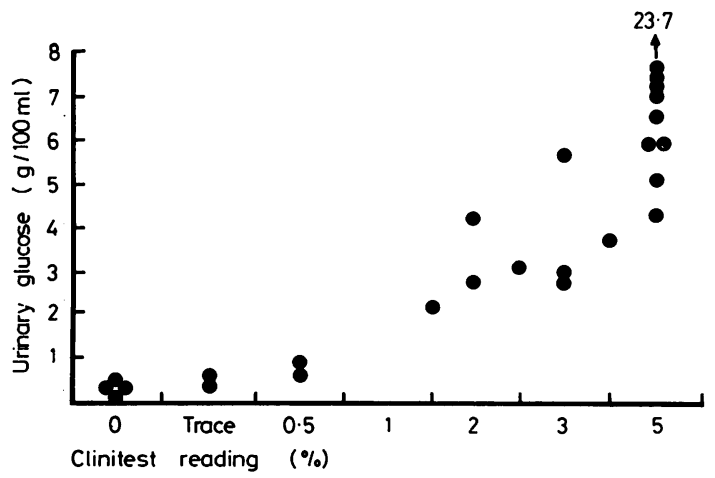

Fig. 1 Correlation of the urinary glucose concentration measured by the glucose analyser and the Clinitest 2-drop method. one colour reading on the 2-drop Clinitest scale but it was apparent that a reading on the Clinitest scale of $5 \%$ indicated a glucose concentration equal to, or greater than, $5 \mathrm{~g} / 100 \mathrm{ml}(278 \mathrm{mmol} / \mathrm{l})$.

Relationship between blood glucose concentration and urinary glucose concentration.

\section{Night time period}

There were 14 overnight urine collections. The relationship between the 'average' nocturnal blood glucose concentration and the urine glucose in the morning specimen is shown in Fig. 2. The correlation is poor and is not statistically significant.

\section{Day time period}

The relationship between the 'average' blood glucose concentration and the corresponding urinary glucose concentration during the day is shown in Fig. 3. The data relate to 10 children and represent 64 blood glucose/urine glucose pairs $(r=0 \cdot 74$; $\mathrm{P}<0.001$ ).

Undetectable glycosuria occurred only with an 'average' blood glucose $<6.4 \mathrm{mmol} / 1.2 \%$ glycosuria indicated an 'average' blood glucose $>8.6$ $\mathrm{mmol} / \mathrm{l}$, and $5 \%$ glycosuria indicated a blood glucose $>11 \cdot 3 \mathrm{mmol} / \mathrm{l}$.

The urine glucose excretion at each voiding was also measured. Fig. 4 shows that with an 'average' blood glucose $<11 \cdot 1 \mathrm{mmol} / 1(<200 \mathrm{mg} / 100 \mathrm{ml})$ the urinary glucose loss is small $(<5 \mathrm{~g} ; 278 \mathrm{mmol})$ but with $>11 \cdot 1 \mathrm{mmol} / 1$ considerable losses may occur.

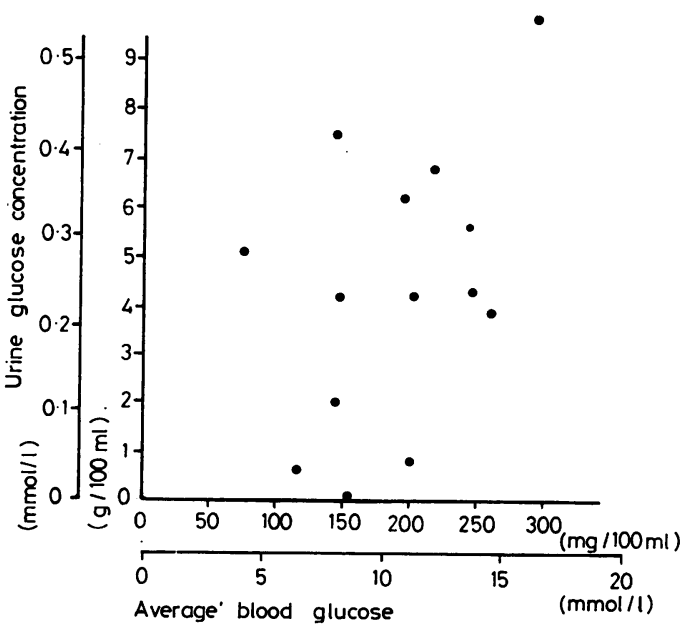

Fig. 2 Relationship between the urinary glucose concentration in the first morning specimen and the 'average' nocturnal blood glucose concentration. The correlation is not significant. 


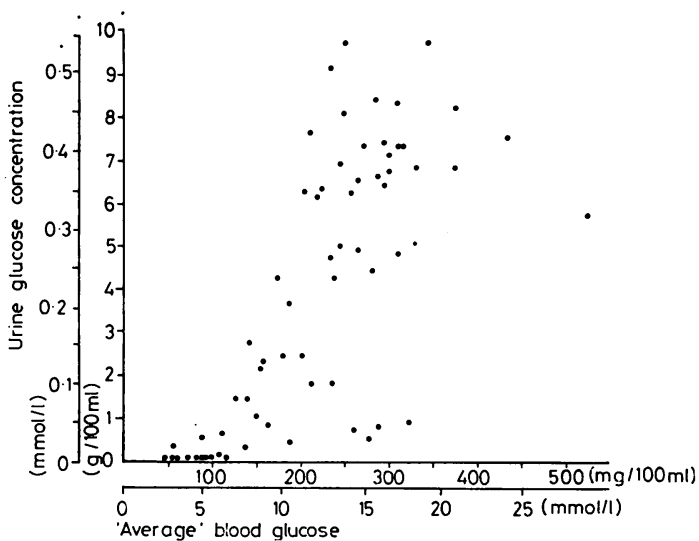

Fig. 3 Relationship between the urinary glucose concentration and the corresponding 'average' daytime blood glucose concentration $(P<0.001)$.

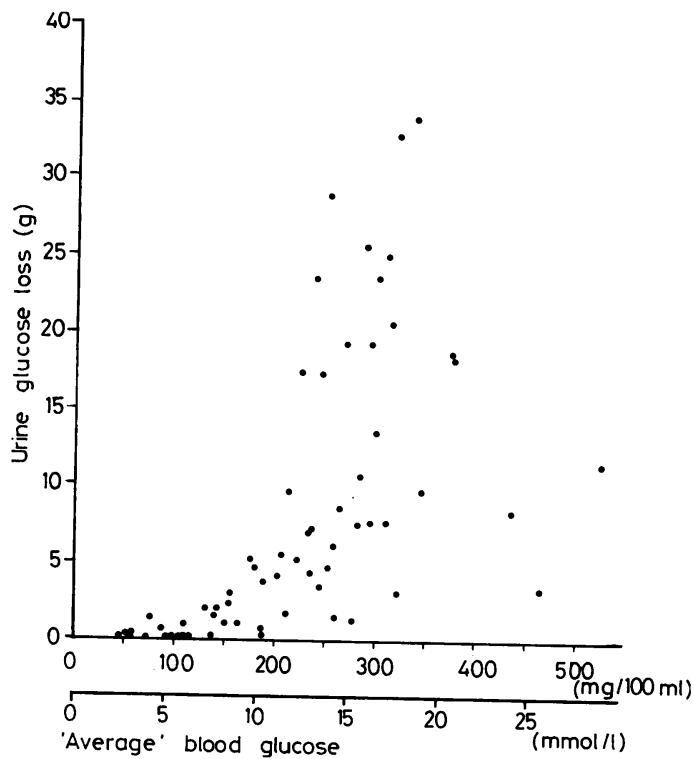

Fig. 4 Relationship between the total urinary loss and the corresponding average daytime blood glucose concentration $(P<0.001)$.

\section{Discussion}

The day-to-day control of diabetic patients is currently judged principally on the urinary glucose concentration measured by the patient using a commercially available kit, such as Clinitest. In Britain the 5-drop method is often used but elsewhere the 2-drop method is more common. It is likely that urine testing will remain the primary index of diabetic control until systems for home monitoring of blood glucose (Sonksen et al., 1978; Walford et al., 1978) are simplified, especially in the case of diabetic children.

The usefulness of urinary glucose measurements in the management of diabetes depends on its accuracy in reflecting the blood glucose concentration. The two measurements are not constantly related as the urine glucose concentration will be influenced by the urine volume, the renal threshold for glucose, and the peak blood glucose levels reached between bladder voidings. These factors may alter from dayto-day because of variations in the patient's activity, fluid intake, and general health, and in qualitative changes in the carbohydrate eaten.

Overnight, changes in blood glucose concentrations occur more slowly but because of the longer time between bladder voidings they are not so accurately reflected by urinary glucose concentrations. The urine glucose may relate to the height of the postprandial blood glucose level the evening before, or to the rising blood glucose in the later hours of the night in patients in whom insulin activity does not completely cover 24 hours. It is, therefore, difficult to interpret the urine glucose concentration on the first specimen voided in the morning unless it is $0 \%$.

During the day urine glucose concentrations give a valid retrospective index of blood glucose levels. Readings of $0 \%$ indicate a blood glucose concentration below the patient's renal threshold since the last urine specimen. Readings of $2 \%$ indicate an 'average' blood glucose $>8.6 \mathrm{mmol} / \mathrm{l}$, and levels of $5 \%$ indicate an 'average' blood glucose $>11.3$ $\mathrm{mmol} / \mathrm{l}$. Furthermore large quantities of glucose may be lost in the urine when the 'average' blood glucose is $>11.1 \mathrm{mmol} / 1$ since the previous voiding (Fig. 4). In order to identify blood glucose concentrations of this level, urine glucose concentrations of 2-5\% must be measurable. With Clinitest tablets this is only possible if the 2-drop method is used. The findings presented here confirm that the additional range of glycosuria detectable is of clinical value, and is achieved without any loss of accuracy at low levels of glycosuria.

N.K.G. was supported by the Medical Research Fund, M.A.S. was supported by a grant from the British Diabetic Association, and G.W. was supported by a grant from the Novo Foundation. Our thanks are due to Ames Co., Slough for providing the 2-drop Clinitest colour charts. 


\section{References}

Belmonte, M. M., Sarkozy, E., and Harpur, E. R. (1967). Urine sugar determination by the two drop Clinitest method. Diabetes, 16, 557-559.

Bergmeyer, H. U. (1974). Methods of Enzymatic Analysis, second edition. Academic Press: New York.

Sonksen, P. H., Judd, S. L., and Lowy, C. (1978). Home monitoring of blood glucose. Lancet, 1, 729-732.
Walford, S., Gale, E. A. M., Allison, S. P., and Tattersall, R. B. (1978). Self monitoring of blood-glucose; improvement of diabetic control. Lancet, 1, 732-735.

Correspondence to Dr N. K. Griffin, Department of Paediatrics, John Radcliffe Hospital, Headington, Oxford OX3 9DU.

Received 27 July 1978 